\title{
LOCATION-PRICE COMPETITION WITH EXTERNALITY: AN APPLICATION TO THE TENERIFE TRAM
}

\author{
Pablo Dorta González*, Dolores Rosa Santos Peñate*, Rafael Suárez Vega* and \\ María Isabel Dorta González ${ }^{\dagger}$ \\ *Universidad de Las Palmas de Gran Canaria, \\ Gran Canaria, España \\ e-mail: pdorta@dmc.ulpgc.es drsantos@dmc.ulpgc.es rsuarez@dmc.ulpgc.es \\ ${ }^{\dagger}$ Universidad de La Laguna \\ Tenerife, España \\ e-mail: isadorta@ull.es
}

2008

\begin{abstract}
This paper presents a location-price equilibrium problem on a tree. A sufficient condition for having a Nash equilibrium in a spatial competition model that incorporates price, transport, and externality costs is given. This condition implies both competitors are located at the same point, a vertex that is the unique median of the tree. However, this is not an equilibrium necessary condition. Some examples show that not all medians are equilibria. Finally, an application to the Tenerife tram is presented.
\end{abstract}

Keywords: duopoly; location; price; externality; equilibrium

\section{INTRODUCTION}

Models in spatial competition involve decisions on location and price (or production) made by firms in a spatial market. Two different approaches are usually considered when firms have to choose the location and the price. Some authors assume a simultaneous choice of price and location. However, most models in this context follow Hotelling's formulation and use a refinement of the Nash equilibrium. More precisely, firms are supposed to choose location and price, one at a time, in a two-stage process, with the aim of maximizing their own profit.

Externalities have been little discussed in the literature on spatial competition. Equilibrium models incorporating location and externality cost have been investigated by $[1,2]$, although in these works there is no competition in price. In [3] a spatial competition model in networks incorporating price and externality cost is proposed. In this model firms are already located and therefore the location equilibrium is not studied. A regulating agent assigns the demand, taking into account the price, transport and externality costs, and minimizes the joint consumer cost in order to obtain a cooperative allocation which is a Pareto optimum. Assuming this cooperative allocation, each firm selects the price, for fixed locations, in order to maximize its profit. For an overview of the problem can consult $[4,5,6]$

The contribution of this work is based on trying, for the first time, location and price decisions in a market where there is externality. Some of the assumptions considered are often made in the economic literature on equilibria, as there is a single good and it is essential (the demand is perfectly inelastic). Considering location on trees is due to the complexity of the problem and the important properties that are satisfied by trees. 
In this paper, cooperative allocation that minimizes the joint consumer cost is assumed, and each firm first selects the location of a facility and then selects the price in order to maximize its profit. A result describes a sufficient condition under which the Nash equilibria on locations and prices are guaranteed. This condition implies that both competitors are located in the same point, that is a vertex that is the unique median of the tree. However, this is not an equilibrium necessary condition. Some examples show that not all medians are equilibria. Finally, an application with real data is presented.

\section{APPLICATION TO THE TENERIFE TRAM}

In 2007 the first line of the Tenerife tram in the metropolitan area 'Santa Cruz-La Laguna', was inaugurated. The length of the line is $12.5 \mathrm{~km}$., with 21 stops, and the tram has a capacity for 200 people. The information about the tram stops, the travelling time between stops, and the number of ticket validations at the tram stops in October 2007, are shown in Table 1. This line, the median, and population density in the metropolitan area, are shown in Figure 1.

\begin{tabular}{llccc}
\hline Node & Tram stop & Time (min.) & Cumulative time & Validations \\
\hline 1 & Intercambiador & - & 0 & 81583 \\
\hline 2 & Fundación & 3 & 3 & 51905 \\
\hline 3 & Teatro Guimerá & 1 & 4 & 90033 \\
\hline 4 & Weyler & 2 & 6 & 99522 \\
\hline 5 & La Paz & 2 & 8 & 64013 \\
\hline 6 & Puente Zurita & 2 & 10 & 46132 \\
\hline 7 & Cruz del Señor & 2 & 12 & 89050 \\
\hline 8 & Conservatorio & 2 & 14 & 14717 \\
\hline 9 & Chimisay & 1 & 15 & 26040 \\
\hline 10 & Principes de España & 2 & 17 & 51155 \\
\hline 11 & Hospital La Calendaria & 2 & 19 & 46604 \\
\hline 12 & Taco & 1 & 20 & 53837 \\
\hline 13 & El Cardonal & 3 & 23 & 17169 \\
\hline 14 & Hospital Universitario & 1 & 24 & 45365 \\
\hline 15 & Las Mantecas & 3 & 27 & 12131 \\
\hline 16 & Campus Guajara & 2 & 29 & 48362 \\
\hline 17 & Gracia & 1 & 30 & 27941 \\
\hline 18 & Museo de la Ciencia & 2 & 32 & 20746 \\
\hline 19 & Cruz de Piedra & 1 & 33 & 36099 \\
\hline 20 & Padre Anchieta & 3 & 36 & 41369 \\
\hline 21 & La Trinidad & 1 & 37 & 115977 \\
\hline Total & & 37 & & 1079751 \\
\hline Tram & stops, travelling time & & & \\
\hline
\end{tabular}

Table 1. Tram stops, travelling time between stops, and the number of ticket validations.

The tram operator 'Metropolitano de Tenerife' (MTSA) is $85 \%$ publicly owned. It has two information offices at stops 1 and 21. These offices deal with customer enquiries and provide general information on the service (routes, timetables, bus connections) as well as information on standard tickets, multi-journey tickets and monthly passes, all of which can be purchased directly from the offices. They also handle complaints and suggestions from customers and act as lost property offices. 


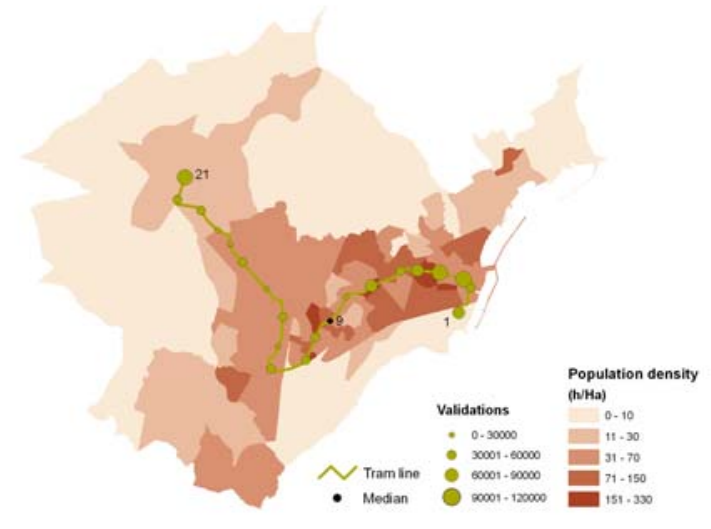

Figure 1. Tenerife metropolitan area and tram stops

At present, the tram operator MTSA is considering the possibility to expanding and relocating the information offices. Furthermore, it is examining the adequacy of outsourcing this service and introducing competition. Table 2 shows the solution to the $\mathrm{p}$-median and $\mathrm{p}$-center problems. The $\mathrm{p}$ median problem consists of determining $\mathrm{p}$ facility locations which minimize the total transport time (efficiency criterion). The p-center problem considers an equity criterion and consists of determining $\mathrm{p}$ facility locations which minimize the longest transport time between a customer and its nearest facility. Many applications of these problems arise both in the public and in the private sectors.

As can be seen in Table 2, the 1-median solution is node 9, that is, the node should be chosen according to the minimization of the transport time of all users. Locating two facilities at nodes 4 and 17 would obtain a reduction in the total transport time of 54\%. By introducing a third facility the additional reduction would be $19 \%$. New facilities produce additional reductions below of $10 \%$. In the present situation (two facilities at nodes 1 and 21), the transport time for all users is $35 \%$ greater than the 2-median solution. In case it is not possible to relocate facilities, a new facility in node 10 reduces this transport time by $49 \%$.

\begin{tabular}{|c|c|c|c|c|c|c|c|c|}
\hline \multirow[t]{2}{*}{$\bar{p}$} & \multicolumn{4}{|c|}{ median } & \multicolumn{4}{|c|}{ center } \\
\hline & solution & time & $\begin{array}{l}\text { reduction } \\
\text { from } p=1\end{array}$ & & solution & time & $\begin{array}{l}\text { reduction } \\
\text { from } p=1\end{array}$ & \\
\hline 1 & 9 & 11461290 & - & & 11 & 19 & - & \\
\hline 2 & 4,17 & 5324918 & $54 \%$ & & 6,15 & 10 & $47 \%$ & \\
\hline 3 & $4,12,20$ & 3212012 & $73 \%$ & & $4,12,19$ & 6 & $68 \%$ & \\
\hline 4 & $3,7,12,20$ & 2364542 & $80 \%$ & & $3,8,13,19$ & 4 & $79 \%$ & \\
\hline 5 & $3,7,12,17,21$ & 1742100 & $85 \%$ & & $3,7,12,16,19$ & 4 & $79 \%$ & \\
\hline \multirow[t]{2}{*}{6} & $1,4,7,12,17,21$ & 1371575 & $88 \%$ & & $2,6,10,14,18,21$ & 3 & $84 \%$ & \\
\hline & 1,21 fixed & time & $\begin{array}{l}\text { reduction } \\
\text { from } p=2\end{array}$ & $\begin{array}{c}\Delta \text { from } \\
\text { no fixed }\end{array}$ & 1,21 fixed & time & $\begin{array}{l}\text { reduction } \\
\text { from } p=2\end{array}$ & $\begin{array}{c}\Delta \text { from } \\
\text { no fixed }\end{array}$ \\
\hline 2 & 1,21 & 8198776 & - & $35 \%$ & 1,21 & 18 & - & $80 \%$ \\
\hline $2+1$ & 1,$21 ; 10$ & 4158064 & $49 \%$ & $23 \%$ & 1,$21 ; 11$ & 9 & $50 \%$ & $50 \%$ \\
\hline $2+2$ & 1,$21 ; 5,11$ & 2761774 & $66 \%$ & $14 \%$ & 1,$21 ; 7,14$ & 6 & $67 \%$ & $50 \%$ \\
\hline $2+3$ & 1,$21 ; 4,7,12$ & 2053556 & $75 \%$ & $15 \%$ & 1,$21 ; 5,10,15$ & 5 & $72 \%$ & $25 \%$ \\
\hline $2+4$ & 1,$21 ; 4,7,12,17$ & 1371575 & $83 \%$ & $0 \%$ & 1,$21 ; 4,7,12,16$ & 4 & $78 \%$ & $33 \%$ \\
\hline
\end{tabular}

Table 2. Solutions to the $p$-median and $p$-center problems $(1 \leq p \leq 6)$

The 1-center solution is node 11 , obtaining in this case a maximum user transport time of 19 minutes. Two facilities at nodes 6 and 15 reduce this time to 10 minutes and a third service reduces this time to 6 minutes. In the present situation (facilities at nodes 1 and 21), the maximum transport time is 18 minutes, $80 \%$ greater than the 2 -center solution. A new facility in node 11 reduces this 
time by half, but it is still $50 \%$ greater than the 3 -center solution. Two nodes in both the median and the center solutions are the same (4 and 12) while the others are close (19 and 20). Therefore, this data suggests the location of at least two facilities at nodes 4 and 17 (or three at nodes 4,12 , and 19 or 20 ).

When there is competition, in equilibrium both competitors locate at the same node, the median of the tree (tram stop 9). In this solution both firms could share the facility, employing their own staff. Therefore, in equilibrium customers would not perceive a difference with respect to who provides the service (all employees with the same uniform, for example). However, with competition the service obtains efficiency minimizing transport and waiting times. In this solution, firms have the incentive of attending the maximum number of customers (increasing the number of employees at peak hours, for example).

\section{CONCLUSIONS}

This work presents a location-price equilibrium problem on a tree. A sufficient condition for having a Nash equilibrium in a spatial competition model that incorporates price, transport and externality costs, is given. This condition implies both competitors are located in the same point, a vertex that is the unique median of the tree. However, this is not an equilibrium necessary condition. Some examples show that not all medians are equilibria. Finally, an application to the Tenerife tram is presented.

\section{REFERENCES}

[1] M. Brandeau and S. Chiu, "Facility location in a user-optimizing environment with market externalities: Analysis of customer equilibria and optimal public facility locations", Location Science, 2, 129-147 (1994a).

[2] M. Brandeau and S. Chiu, "Location of competing private facilities in a user-optimizing environment with market externalities", Transportation Science, 28, 125-140 (1994b).

[3] P. Dorta-González, D.R. Santos-Peñate and R. Suárez-Vega, "Pareto optimal allocation and price equilibrium for a duopoly with negative externality", Annals of Operation Research, 116, 129-152 (2002).

[4] P. Dorta-González, D.R. Santos-Peñate and R. Suárez-Vega, "A duopolistic spatial competition model with non-zero conjectural variation", Top, 14, 113-134 (2006).

[5] P. Dorta-González, D.R. Santos-Peñate and R. Suárez-Vega, "Spatial competition in networks under delivered pricing", Papers in Regional Science, 84, 271-280 (2005).

[6] P. Dorta-González, D.R. Santos-Peñate and R. Suárez-Vega, "Cournot oligopolistic competition in spatially separated markets: The Stackelberg equilibrium", The Annals of Regional Science, 38, 499-511 (2004). 